Original Article

\title{
The relationship between physical capacity and fear avoidance beliefs in patients with chronic low back pain
}

\author{
Juhwan Lee, PT, MS ${ }^{1)}$, ShinJun Park, PT, MS ${ }^{1 *}$ \\ 1) Department of Physical Therapy, Graduate School, Yongin University: 134 Yongin Daehakro, \\ Chuhingu, Yonginshi, Kyunggido 449-714, Republic of Korea
}

\begin{abstract}
Purpose] The aim of this study was to investigate the relationship between physical capacity and fear avoidance beliefs in patients with chronic low back pain. [Subjects and Methods] This cross sectional study included 131 male university students with chronic low back pain. All the patients completed a fear avoidance beliefs questionnaire. Each participant performed a physical capacity test, which included hand grip force, leg strength, abdominal muscle endurance, flexibility, and cardiopulmonary endurance testing. [Results] Negative correlation was observed between physical capacity (leg strength, abdominal muscle endurance) and fear avoidance beliefs regarding work. Physical capacity (hand grip force, leg strength, cardiopulmonary endurance) showed a negative correlation with fear avoidance beliefs about physical activity. Abdominal muscle endurance and cardiopulmonary endurance were predictors of fear avoidance beliefs. [Conclusion] Physical capacity showed a negative correlation with fear avoidance beliefs in patients with chronic low back pain. The results of this study suggest that physical capacity is an important factor for predicting fear avoidance beliefs in patients with chronic low back pain. Key words: Chronic low back pain, Fear avoidance beliefs, Physical capacity
\end{abstract}

(This article was submitted May 31, 2017, and was accepted Jun. 20, 2017)

\section{INTRODUCTION}

Fear avoidance beliefs (FAB) has been reported to cause chronic low back pain (CLBP) ${ }^{1,2}$. According to the FAB model, when an injury occurs, patients experience pain and avoid movement due to the fear of pain. In the long run, this can result in insomnia, depression, and disability ${ }^{3}$. In previous studies, FAB exacerbate the response to physical therapy ${ }^{4}$, and show a positive relationship with the activity of core muscle in patients with chronic low back pain ${ }^{5)}$. On the other hand, physical fitness is closely related to the improvement of cognitive ability and psychological factors. Cognitive ability may improve with increased strength and aerobic exercise ${ }^{6}$. Higher aerobic capacity, muscle strength, and flexibility were the physical capacity variables that contributed to less symptoms of depression ${ }^{7}$. To our knowledge, there are no prior studies that demonstrate the relationship between physical capacity (PC) and FAB in CLBP patients. Although Demoulin et al..$^{8}$ performed a regression analysis to identify the effect of PC on FAB, PC was limited to flexibility, strength, and endurance of the back muscles with no objective assessments. Verbunt et al. $\left.{ }^{9}\right)$ has also reported the correlation between PC and FAB. In addition, in this article, the measurements of PC included cardiopulmonary capacity and an unreliable questionnaire. Therefore, the purpose of this study was to investigate the relationship between PC (measured by hand grip force, leg strength, abdominal endurance, flexibility, and cardiopulmonary endurance) and FAB using objective evaluation equipment and a reliable questionnaire in CLBP patients.

*Corresponding author. Shinjun Park (E-mail: 3178310@naver.com)

(C2017 The Society of Physical Therapy Science. Published by IPEC Inc.

(c) (1) $\odot$ This is an open-access article distributed under the terms of the Creative Commons Attribution Non-Commercial No Deriva-

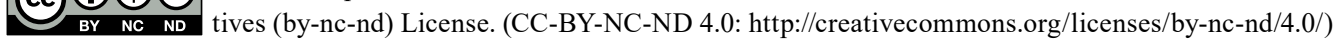




\section{SUBJECTS AND METHODS}

A total of 131 male university students, who were treated at the clinic of orthopedic surgery in Gyeonggi Province, were included in this study. The inclusion criterion was a history of non-specific LBP with symptoms lasting longer than 3 months. Individuals were excluded if they had a history of back surgery, a neurologic disorder, or other musculoskeletal disorders. Also, those who complained of pain during physical capacity test were excluded from this study. The average age was 21.6 \pm 1.3 years old ( \pm SD [standard deviation]); the average height was $175.9 \pm 5.5$ inches; and the average weight was $72.8 \pm$ 11.1 kilograms, with an average BMI of $23.5 \pm 3.2$. Participants completed the fear avoidance beliefs questionnaire (FABQ). Subsequently, PC was measured by objective equipment. Yongin University's research ethics board approved the study protocol (2-1040966-AB-N-01-20-1603-HSR-050). All subjects provided informed consent for their inclusion in the study. FAB was evaluated by using the Korean version of the FABQ, which showed good test-retest reliability: $\operatorname{ICC}(3,1)=0.90$ (FABQ for physical activity) and 0.97 (FABQ for work) ${ }^{10)}$. PC was measured using the Inbody u-town health fitness test (Biospace Co., Ltd.). Hand grip force (HGF), leg strength (LS), abdominal muscle endurance (AME), flexibility (FB), and cardiopulmonary endurance (CE) were measured as part of the physical capacity variables. The HGF test was performed for 3 seconds with the subject's dominant 2nd-5th mid-phalanx fingers facing the handle. LS was measured based on results from an isotonic dynamometer on the dominant side. Two submaximal trials were performed. AME was determined based on the number of sit-ups completed in 30 seconds. A sit and reach test was also conducted to quantify FB with a digital measuring instrument. The best result of the 2 trials was reported for HGF, LS and FB. CE was assessed with a seated bicycle trial after the resting heartbeat was monitored for 1 minute. Each subject was positioned with their knees flexed at a 10-degree angle, and instructed to maintain a speed of 50-60 revolutions per minute (RPM) for 6 minutes. Once completed, their heart rate was measured and compared to their resting heart rate. We then used the Pearson correlation to examine the relationship between PC and FAB. A stepwise, multiple regression analysis was used to identify the predictors of PC in FAB in CLBP patients. Analysis was performed using SPSS for Windows (version 21.0), with statistical significance considered to be a p-value of less than 0.05 .

\section{RESULTS}

The mean values and SD of HGF, LS, AME, FB, CE, fear avoidance beliefs about work (FABW), fear avoidance beliefs about physical activity (FABPA) were $42.7 \pm 6.7 \mathrm{~kg} . f, 48.2 \pm 12.9 \mathrm{~kg} . f, 18.1 \pm 7.4,-1.9 \pm 11.5 \mathrm{~cm}, 47.5 \pm 9.7 \mathrm{ml} / \mathrm{kg} / \mathrm{min}$, $25.5 \pm 8.1$, and $15.8 \pm 4.7$, respectively. LS and AME were negatively correlated with FABW (Table 1); and HGF, LS, CE were negatively correlated with FABPA (Table 2). In the stepwise multiple regression, AME was a significant predictor of FABW; and LS and CE were significant predictors of FABPA (Table 3).

\section{DISCUSSION}

Patients with greater leg strength are more likely to perform independently in their activities of daily living ${ }^{11)}$, and also abdominal muscle strength has a significantly positive correlation with activities of daily living and balance ${ }^{12)}$. Waddell et al. ${ }^{13)}$ found that FABW was a predictor of disability for independent activities of daily living. Therefore, it is considered that there is a significant correlation between LS, AME, and FABW in this study. Additionally, the subjects in this study were university students. University students spent eight hours per day on sedentary activities ${ }^{14}$ ). As the sitting time increased, the AME decreased and lower levels of AME were closely related to lower levels of activities of daily living ${ }^{15)}$. Therefore, it is considered that if AME is weak, the sitting posture maintenance time will be reduced, which can affect the students' ability to work. AME appeared as predictor of FABW in this study.

On the other hand, there was a significantly negative correlation between pain intensity and muscle strength of the leg and hand on the side with pain ${ }^{16}$. There was also an increase in pain intensity that increases with the FABPA, leading to less use, which further contributes to the severity of pain. Therefore, it is considered that a correlation exists between the muscle strength of the hand and leg and FABPA. Also, a hesitation to remain active can have a detrimental effect on the cardiopulmonary system, as well as on the musculoskeletal system ${ }^{17)}$. This may be the cause of the significant correlation between $\mathrm{CE}$ and FABPA. In the present study, CE appeared to be a predictor of FABPA in the regression analysis. FAB was a predictor of an isometric spinal muscle deficit ${ }^{18)}$. Also, the time increase of static movement is closely related to lower $\mathrm{CE}^{19)}$. Therefore, it seems that CE may have influenced FABPA in this study. Maintaining the daily activities that are related to physical abilities can sustain and even increase $\mathrm{CE}^{20)}$. Therefore, it is necessary to maintain daily activity to improve FABPA of patients with chronic low back pain. The present study has some limitations. Because this study was a cross-sectional study, it is difficult to ascertain causation, although there is a correlation between FAB and PC. Therefore, future prospective research is necessary to further explore this relationship. In addition, the subjects in the present study are male, university students and do not represent all subjects. Future studies should include a more diverse sample that would allow for generalized result that could be applicable across patients of different age groups and genders. 
Table 1. Relationship between PC and FABW of the participants $(\mathrm{N}=131)$

\begin{tabular}{lc}
\hline Variables & FABW \\
\hline LS & $-0.180^{*}$ \\
AME & $-0.193^{*}$ \\
\hline PC: physical capacity; FABW: fear \\
avoidance beliefs about work; LS: leg \\
strength; AME: abdominal muscle en- \\
durance \\
${ }^{*} \mathrm{p}<0.05$
\end{tabular}

Table 2. Relationship between $\mathrm{PC}$ and FABPA of participants $(\mathrm{N}=131)$

\begin{tabular}{ll}
\hline Variables & FABPA \\
\hline HGF & $-0.184^{*}$ \\
LS & $-0.177^{*}$ \\
CE & $-0.263^{* *}$ \\
\hline PC: physical capacity; FABPA: fear \\
avoidance beliefs about physical activity; \\
HGF: hand grip force; LS: leg strength; \\
CE: cardiopulmonary endurance \\
${ }^{*} \mathrm{p}<0.05, * * \mathrm{p}<0.01$
\end{tabular}

Table 3. Stepwise multiple regression between PC and FAB ( $\mathrm{N}=131)$

\begin{tabular}{llccccc}
\hline Variables & Independent variables & $\mathrm{B}$ & $\mathrm{SE}$ & $\beta$ & $\mathrm{R}^{2}$ & $\mathrm{p}$ \\
\hline FABW & AME & -0.21 & 0.09 & -0.19 & 0.037 & 0.027 \\
FABPA & CE & -0.12 & 0.04 & -0.26 & 0.062 & 0.02 \\
\hline
\end{tabular}

PC: physical capacity; FAB: fear avoidance beliefs; FABW: fear avoidance beliefs about work; FABPA: fear avoidance beliefs about physical activity; AME: abdominal muscle endurance; $\mathrm{CE}$ : cardiopulmonary endurance

\section{REFERENCES}

1) Buer N, Linton SJ: Fear-avoidance beliefs and catastrophizing: occurrence and risk factor in back pain and ADL in the general population. Pain, 2002, 99: 485-491. [Medline] [CrossRef]

2) Linton SJ, Shaw WS: Impact of psychological factors in the experience of pain. Phys Ther, 2011, 91: 700-711. [Medline] [CrossRef]

3) Vlaeyen JW, Linton SJ: Fear-avoidance and its consequences in chronic musculoskeletal pain: a state of the art. Pain, 2000, 85: 317-332. [Medline] [CrossRef]

4) Feitosa AS, Lopes JB, Bonfa E, et al.: A prospective study predicting the outcome of chronic low back pain and physical therapy: the role of fear-avoidance beliefs and extraspinal pain. Rev Bras Reumatol, 2016, 56: 384-390 (in Portuguese). [Medline] [CrossRef]

5) Massé-Alarie H, Beaulieu LD, Preuss R, et al.: Influence of chronic low back pain and fear of movement on the activation of the transversely oriented abdominal muscles during forward bending. J Electromyogr Kinesiol, 2016, 27: 87-94. [Medline] [CrossRef]

6) Colcombe S, Kramer AF: Fitness effects on the cognitive function of older adults: a meta-analytic study. Psychol Sci, 2003, 14: 125-130. [Medline] [CrossRef]

7) McQuade KJ, Turner JA, Buchner DM: Physical fitness and chronic low back pain. An analysis of the relationships among fitness, functional limitations, and depression. Clin Orthop Relat Res, 1988, (233): 198-204. [Medline]

8) Demoulin C, Huijnen IP, Somville PR, et al.: Relationship between different measures of pain-related fear and physical capacity of the spine in patients with chronic low back pain. Spine J, 2013, 13: 1039-1047. [Medline] [CrossRef]

9) Verbunt JA, Seelen HA, Vlaeyen JW, et al.: Fear of injury and physical deconditioning in patients with chronic low back pain. Arch Phys Med Rehabil, 2003, 84: 1227-1232. [Medline] [CrossRef]

10) Joo MK, Kim TY, Kim JT, et al.: Reliability and validity of the Korean version of the fear-avoidance beliefs questionnaire. Phys Ther Korea, 2009, 16: 24-30.

11) den Ouden ME, Schuurmans MJ, Arts IE, et al.: Association between physical performance characteristics and independence in activities of daily living in middle-aged and elderly men. Geriatr Gerontol Int, 2013, 13: 274-280. [Medline] [CrossRef]

12) Karatas M, Çetin N, Bayramoglu M, et al.: Trunk muscle strength in relation to balance and functional disability in unihemispheric stroke patients. Am J Phys Med Rehabil, 2004, 83: 81-87. [Medline] [CrossRef]

13) Waddell G, Newton M, Henderson I, et al.: A Fear-Avoidance Beliefs Questionnaire (FABQ) and the role of fear-avoidance beliefs in chronic low back pain and disability. Pain, 1993, 52: 157-168. [Medline] [CrossRef]

14) Rouse PC, Biddle SJ: An ecological momentary assessment of the physical activity and sedentary behaviour patterns of university students. Health Educ J, 2010, 69: 116-125. [CrossRef]

15) O'Sullivan PB, Mitchell T, Bulich P, et al.: The relationship beween posture and back muscle endurance in industrial workers with flexion-related low back pain. Man Ther, 2006, 11: 264-271. [Medline] [CrossRef]

16) van Wilgen CP, Akkerman L, Wieringa J, et al.: Muscle strength in patients with chronic pain. Clin Rehabil, 2003, 17: 885-889. [Medline] [CrossRef]

17) Bortz WM 2nd: The disuse syndrome. West J Med, 1984, 141: 691-694. [Medline]

18) Al-Obaidi SM, Nelson RM, Al-Awadhi S, et al.: The role of anticipation and fear of pain in the persistence of avoidance behavior in patients with chronic low back pain. Spine, 2000, 25: 1126-1131. [Medline] [CrossRef]

19) Martinez-Gomez D, Ortega FB, Ruiz JR, et al. HELENA study group: Excessive sedentary time and low cardiorespiratory fitness in European adolescents: the HELENA study. Arch Dis Child, 2011, 96: 240-246. [Medline] [CrossRef]

20) American College of Sports Medicine: American College of Sports Medicine position stand. The recommended quantity and quality of exercise for developing and maintaining cardiorespiratory and muscular fitness in healthy adults. Med Sci Sports Exerc, 1990, 22: 265-274. [Medline] 